treatment, the discharge and other symptoms subsided, but very considerable deafness remained, and the perforation did not beal.

CASE 7.-On November 10th, 1874, Mr. G. B-, aged fifty-seven, gave me the following account:-Whilst out cover-shooting a long thorn ran into the left ear. This was followed by acute pain, a loud report, and a little bleeding. By the next day there was no uneasiness or deafness.

When I saw him, long after the accident, there was a distinct scar in the posterior section of the membrane. An unmistakable appearance of scars in the membrane is not at all usual. The hearing was not quite so good as with the other ear, but he was not conscious of any difference until it was carefully tested.

By the side of this case I place another, where almost precisely the same accident occurred.

CASE 8.-A gentleman about thirty years of age was covershooting in the winter of 1873, and turning his head suddenly round to shoot at a rabbit, a twig of hazel-tree ran into the left ear and gave him great pain. I examined the ear two days afterwards. There was a small perforation in the posterior section of the membrane. This healed in two days, leaving the hearing unimpaired. So clearly was this the case that, in making a report on the matter to the Accidental Insurance Office in which the patient was insured, I described the hearing as having suffered no injury whatever.

CASE 9.- On November 11th, 1874, Mr. J-, aged thirty-five, applied to me for advice on account of an rccident which occurred in this manner:-Three weeks before, he had in his sitting-room put together a fishing rod, and, on suddenly turning round in play with one of his children, had run the brass ring at the end of the last joint of the rod into his right ear, and perforated the membrane. The accident was followed by great pain, inflammation of the tympanic cavity, a profuse discharge from his ear, and extensive deafness. The inflammation had, when I saw him, extended from the tympanum to the mastoid cells; the tissues over the mastoid process were swollen, the surface was red and acutely tender to the touch, and he was in great suffering. All traces of the tympanic membrane were gone; there was a purulent discharge, and the deafness was extreme. Under the influence of leeches and hot fomentations the acute symptoms subsided, and the patient did not present himself again until January, 1875, at which time there was a profuse discharge from the ear, and the meatus was partially filled with a fleshy polypoid growth. This was removed by forceps, and the granular surface was treated with astringents. All trace of the tympanic membrane was gone, and the hearing considerably impaired. With the use of the cotton-wool support the hearing became fairly good, and the discharge ceased.

CASE 10. - On Nov. 17th, 1874, Mr. W. D- consulted me with history as follows:- Up to July last he had good hearing, and never any trouble with his ears. During that month, in consequence of a stuffed feeling in his ears (which had only lasted a few hours), he forcibly inflated them, and in doing so the air passed through the right ear; he felt a loud crack at the time, together with acute pain. A few days afterwards a discharge appeared, and had been persistent ever since.

I found two small slit-like perforations, with red edges, one on either side of the handle of the malleus. The deaf ness was considerable. The perforations were very small, air passing freely through them. They presented not at al an unhealthy appearance. Whether they will eventually heal or not I cannot say, as the patient sailed the next day for Austrnlia.

CASE 11.-On Dec. 17th, 1874, whilst a young gentleman aged twenty was seated at the table, his brother gave him a sound box on the ear. This was instantly followed by considerable deafness and tinnitus. On examination of the ear on the following day, I found a vertioal slit-like rupture in front of the handle of the malleus to the extent of about half the membrane. He could hear the tick of a watch only when pressed close to the ear, and was very deaf to ordinary sounds. In five days the rupture was quite healed. From the time at which the accident occurred the hearing power gradually returned, until in the course of a fortnight it was of the normal standard, and the tinnitus had quite subsided.

C.sฐ12,- On Jan. 1st, 1875, I examined the right ear of a gentleman aged sixty-two, who had become suddenly deaf three weeks before while an attempt was being made to remove some cerumen from the ear with forceps. Previously to this the hearing had been good. There was a small perforation with red edges in the upper part of the posterior section of the membrane, and a very slight discharge. The hearing was subsequently improved in some degree, but the perforation has not closed, so that in all probability healing will not take place.

It will be observed from the foregoing cases, as well as from the ten others previously reported, that the conditions which eventually remained, either as to continuity in the membrane or hearing power, were various in the extreme, and this, at first sight, irrespective of the manner in which the accident occurred or the size of the original perforation. Out of the twenty-two cases, the perforation did not heal in ten; eleven healed, and one was in the process of healing when last seen; in six instances the hearing did not suffer at all ; in the remaining sixteen it was more or less seriously impaired. But a return to good hearing by no means always followed the closure of the perforation, and in many instances, when the wound healed, the patients were far more deaf than in others where a purulent discharge continued through the opening into the tympanum. Sowe must look for causes to the impairment of function altogether independent of the lesion, so far as can be seen. There can, I think, be little question but that the chief of these is shock to the nervous structures behind the tympanum at the time of the accident. To take, in the first place, the instances where the rupture healed rapidly without any suppuration in the tympanic cavity. From the time of the occurrence of the accident the hearing never varied, and vibrations of sound conveyed through the bones of the head (the sound from a vibrating tuning-fork on the vertex, for instance) were heard less loudly on the affected than on the nonaffected side; in fact, the perception to sound was affected while the conduction through the tympanum was not. This is what happens in the deafness which follows a blow on the head, a box on the ear, or an explosion near the ear, where no rupture of the membrane takes place. In trath, in instances of this kind the hearing is generally more irreparably injured than when the membrane has given way. On the other hand, when suppuration in the tympanic cavity follows the accident, the conduction of sound as well as the perception of sound becomes affected, and so we find that a vibrating tuning fork placed on the head will be heard far more loudly by the injured than by the healthy ear. Thus the products of inflammation in the tympanic cavity become the second element which impairs the hearing.

\section{THE TREATMENT OF PRIMARY DISEASES OF THE HEART.}

Br J. MILNER FOTHERGILL, M.D., Mr.R.C.P., JUNYOR PHYSTCIAT TO THR WEST LONDON HOSPITAL. (Concluded from page 721.)

Even where dilatation of the ventricular chambers is associated with valvular disease, much may be done by treatment. Especially is this the case with disease of the aortic and mitral valves; valvular affections of the right side of the heart being less amenable to treatment. We all know that, in aortic stenosis, by increasing the strength of the left ventricle an equal amount of blood can be driven through a narrowed orifice in an equal time, and so perfect compensation may be attained, as is seen in the simple hypertrophy commonly met with ziaturally in aortic stenosis. Here digitalis is of the greatest service, if the hypertrophy be insufficient and incomplete. In mitral disease the use of digitalis is more generally admitted than in the case of discase of the aortic valves. Yet I venture to say that wo have not yet learned all that digitalis can do-in the case of mitral regurgitation at least.

A brief digression here is desirable: it is in relation to the valvular vela and their ostia. In England many hold the opinion that in pronounced dilatation of the ventricles 
the auriculo-ventricular ostia stretch until the valves become incompetent to close them; that, in fact, we can have valvular insufficiency, with integrity of the valves, by mere dilatation of the ostia. Such was the foundation of the exploded "safety-valve action of the tricuspid" theory of the late Wilkinson King. Rokitansky says that the valvular vela stretch along with the muscular chambers and ostia while Oppolzer and Kürschner state that such valvular incompetency is anatomically impossible. In the case of the mitral valve, Wilkinson King found that it was equal to closing the ostium even when the flaccid dead left ventricle was distended to the utmost, a little leakage happening occasionally only. In fact, the mitral valve is rather more than equal to closing the left auriculo-ventricular ostium on the ventricular contraction. When, however, the mitral valve has become the subject of valvulitis, and its distensibility has been arrested by a deposit of connective tissue in its vela, then ventricular dilatation may lead to mitral insufficiency. Here reduction in the size of the ventricular chamber and the ostium will once more render the witral valve sufficient and competent. We are all aware that dilatation with more or less of hypertrophy of the left ventricle is the common accompaniment of mitral insufficiency.* The following case illustrates admirably what may be done by well-directed treatment in such cases; unfortunately, however, such an excellent result is too rarely attained.

T. B-, aged eighteen, a clerk in the City, bad rheumatic fever in January, 1874, and came under my care on April 20 th of that year. He had then a distinct regurgitant mitral murmur, and an enlarged left ventricle, with an irregular pulse. He had also shortness of breath on exertion, felt very unequal to his work, was troubled with unpleasant dreams, and was pale and anæmic. Under digitalis and iron, as much quiet as was compatible with the continuance of his duties, long hours in bed, \&c., he improved very much; indeed, made that improvement which experience would have led me to expect. On November 6 th he showed himself again, when, to my astonishment, the murmur which had been audible at the left scapula was no longer to be detected. The heart was almost normal in size, and the patient declared that he felt well, and that his wind was nearly as good as ever, while he was now quite equal to his work.

I was so gratified with this result that I sent him on to Dr. Broadbent, who was kind enough to examine him, and who wrote me to the following effect:- "There seems now to be very little hypertrophy or dilatation of either chamber, and I find no murmur; but the pulmonary second sound is still loud, and there is a strident reduplication of the first just within the apex." I think that in this case the assertion may fairly be male that the injured mitral valve is once more equal to closing the ostium, now that the dilated muscular wall and ostium have regained their normal size, or, in other words, that almost the equivalent of a cure bas been attained; with the difference only, indeed, that the mitral valve has lost much of its spare power, and that slight ventricular dilatation will in the future reveal its impaired condition. On Feb. 10 th his condition was unchanged. On May 8 th it was unaltered.

I am the more inclined to assume this, as we know how the mitral valve becomes incompetent, in advanced aortic regurgitation, when the ventricalar wall commences to yield. In such cases the mitral vela are injured, and do not stretch with the enlarging wall and ostium. Dr. Brondbent has shown me a striking case in point in one of his patients at St. Mary's Hospital, where this secondary mitral failure came on in a young man with aortic regurgitation. $\mathrm{O}$ wing to an intercurrent ailment the youth was confined to bed, the consequence of which was the mitral murmur is gone; and to all appearance the effect of the rest upon the ventricle has been to render the mitral valve once more effective. This case, taken with the one I sent on to Dr. Broadbent, suggests in the strongest manner what treatment may achieve in cases of mitral insufficiency.

$$
\text { * Niemeyer, vol. i., p. } 353 \text {. }
$$

t An equally good result has been attained in a patient at the west London Hospital. The patient, a boy of fifteen, came under care on the $13 \mathrm{th}$ of October, last year, with mitral regurgitation following rheumatic fever. To-day (May 24th) he declared he felt well, and on examination neither maining.

$\ddagger$ In Dr. Broadbent's case the mitral insuffiency is returning with the resumption of actire habits.
We are all familiar with the good effects of digitalis in the free bronchial flow and dyspnos of advanced mitra disease. Though by its action upon the right ventricle the blood-pressure in the pulmonic circulation is increased, the bronchorrbca is checked and the breathing is relieved. One of the best cases of relief so afforded is that of a Westmorland peasant, who had rheumatic fever eighteen years ago, under the care of $\mathrm{my}$ late father. The treatment of digitalis and iron commenced by him was continued by myself whenever the symptoms became aggravated, and especially in the attacks of congestion of the lungs with hæmoptysis to which at intervals he was liable. During this time he has laboured continuously, but at light work of course. $\mathrm{He}$ writes me, Jan. 20th: " My general health is better than it was, due probably to my improved means. I have not required anything stronger than mustard as a blister for three years; but the slightest cold causes a spitting of blood, seldom for more than a day, and only a small quan. tiby. At these times there is sudden quick throbbing of the heart, followed by a feeling of suffocation for ten or fifteen minutes; sometimes the throbbing goes off, leaving nothing disagreeable. Pulse regular, but sometimes very low. I go to work every day, but of course I choose a light job. $\mathrm{My}$ locomotives are as good as many of my age if $I$ had the steam to propel them."

The use of digitalis in aortic regurgitation is a matter in which some difference of opinion exists. Many forbid its use here altogether, while others are in favour of its administration. I am inclined to think that it may be harmful or useful according to the stage of the disease. In the earlier stages of massive hypertrophy of healthy muscular fibre its use is objectionable. A brief consideration of the condition of matters will render this intelligible. The hypertrophy bere is not to overcome any obstruction offered to the blood-flow, but to check and limit the dilatation of the let ventricle, now exposed to the distending force of the regurgitant current driven in by the recoil of the aorta Without hypertrophy the ventricle would be rapidly dilated beyond the point of recovery by this new force. The hypertrophy here is conservative, and yet it is not without alloy. The enlarged and powerful ventricle at each systole throws a hage mass of blood into the arteries, and quick and extreme distension follows, so that atheroma of the aorta and other large arteries results. Here to give digitalis, and so to produce still more powerful ventricular contraction, is decidedly objectionable, and its use is contra-indicated. At this stage quiet and avoidance of effort are the best measures for conserving the compensatory growth. If we had a medicinal agent the opposite of digitalis-which would diminish the force of each contraction, and at the same time increase the number per minute-its use would be indicated.

If such is the case at the earlier stages of aortic regurgitation a very different state of affairs, however, obtains in the later stages. When the ventricle is beginning to fail. from fatty degeneration of the hypertrophied walls, then digitelis may be given with advantage. In evidence I may quote Clifford Allbutt "On the Effects of Overwork and Strain upon the Heart and Great Vessels" as to a collier, B. B-_-aged forty-five, who had undergone heavy labour, and was suffering from double aortic disease, and was a patient in the Leeds Dispensary. "Though a man in this condition," says Dr. Allbutt, "has about as bad a form of heart disease as exists, yet by rest, digitalis, and steel much may be dore frr him, as is remarkably well seen in a patient of mire suffering under such mischief, who is now being treated at the dispensary by Dr. Fothergill." The relief afforded in this case, where there were terribly long intermissions, and the man was confined to bed when he first came under care, was very marked; and as long as the man refrained from labour he was fairly comfortable. So well did he feel that he was tempted to enter the pit once more, but the trial ended in death at an early date. An experience of a larme number of such cases inclines me to regard digitalis as very useful when the compensatory hypertrophy is wearing out, but only as a palliative measure-as a means of prolonging life.

In maintaining the action of the right ventricle, when ultimately failing from left side disease or chronic lung disease, remedial measures are very desirable. Large hot poultices to the chest are here very useful. They not only relieve the venous congestion by dilating the cutaneous 
vessels of the trunk, but the effect of heat upon the heart is to distinctly increase the vigour of the ventricular contractions. It is not only in chronic cbanges in the right ventricle that treatment will do good, and means calculated to maintain the ventricular action be beneficial; in the more acute conditions of failure of the right heart, as in bronchitis, pneumonia, and other states where the pulmonic circulation is affected, the means of acting directly upon the ventricle by medicinal agents are often of the greatest service. In such cases the pulse mounts and then intermits; there is much excitement in the distended rigbt ventricle, which is becoming exhausted by the labour it has had to perform. We all recognise the peril associated with such a condition, and the imminent danger which encom. passed the patient. Under these circumstances digitalis, combined with diffusible stimulants, is clearly indicated, and produces the most satisfactory change in many cases. It is superfluous to cite a case illustrative of this condition. When the tricuspid valve is affected little or nothing can be done by treatment.

In cases of right side distension from prolonged overexertion, as in professional runners, swimmers, athletes, \&c., commonly known as cases of cardiac asthma, the value of rest, digitalis, and iron is quickly seen in the good results attained. The lost wind is recovered and the bottom is as good as ever in some cases; in others only imperfect repair is attained. In all cases resort to medical care is clearly indicated.

Increasing physiological and pathological knowledge, together with more careful observation of the effects of remedies and the indications for their use, point out to us very distinctly the objects at which we must aim in the treatment of primary disease of the heart, if we wish it to be successful. The cases given above will tend to demonstrate that this is not a mere hypothesis, but a simple expression of what may be actually attained. Of course no remedies will render compensatory growth permanent, nor dissolve out the connective tissue which contorts the free edges of a valve; neither can unpleasant symptoms be kept at bay for long in cases which are going rapidly and inevitably from bad to worse. Nevertheless, much may be done in very many cases, and life may be prolonged, even where there no longer exists the capacity to labour. Recent experience is demonstrating on both sides of the Atlantic that much may be done for both functional and organic diseases of the heart by well-selected measures, both in the way of preventive and of therapeatic treatment.

of preventive measures nothing can be said at present but of measures palliative or curative the following brief summary may be made:-

1. That it is of the utmost importance in the treatment of primary disease of the heart to reduce to a minimum the calls upon that organ. Consequently light labour alone must be attempted; and rest in bed is often very desirable at the commencement of a course of treatment, as well as at intervals afterwards.

2. Frequently much relief can be afforded when dropsy is present by abloading the distended venous system. Brisk catharsis gives great relief, and does not depress the patient, as might be apprebended.

3. In all cases the heart must be acted upon directly by agents which increase the vigour of the ventricular contractions, of which digitalis is the chief. This agent mas be given uninterruptedly for years without any so-called camulative action, if the cases are properly selected. If given in improper cases unpleasant consequences may follow its administration.

4. It is also very desirable that the nutrition of the heart be maintained by good food and iron in addition to the means mentioned above. Improvement in the general condition facilitates the action of the special semedies.

By a combination of these measures, adapted to the needs of each individual case, much may be done in cases of primary disease of the heart. What are the indications for treatment and the measures to be resorted to in cases of secondary affections of the heart-that is, where the heart-failure is due to some primary ailment standing in a causal relationship to it-will engage out attention on some future occasion.

Lower Seymour-street, W.
ON THE

CONVERSION OF MR. WAKLEY'S STRICTURE DILA'TOR INTO A CATHETER STAFF WITH SLIDING CATHETER FOR URETHROTOMY.

Bx W. F. TEEVAN, B.A., F.R.C.S.,

SURGEON TO THE WEST LONDON AND ST. PETER'S HOSPITALS, AND IAT LECTURER ON ANATOMY AT THE WBSTMMNSTER HOBPITAL.

IF the last editions of the various English surgical textbooks be examined, it will be found that the staff illustrated and described for the performance of external urethrotomy is much the same as the one which Tolet, the inventor of the operation, used two centuries ago. True it is that some few surgeons have divided strictures on a hollow staff, and that others have employed a catheter staff; but I am not aware of any staff in use by the profession which is free from both the objections which attach to the common staff for urethrotomy. When the ordinary staff has been passed down the urethra, the question to be asked is this: Where has it gone to?-is it in the bladder? Unless this interrogatory can be affirmatively answered, the surgeon who operates is exposing his patient to risk. It is not sufficient for the surgeon to say that he thinks the instrument is in the bladder; he ought to be sure that it is there, as surgeons have before now operated when they thought the staff was in the bladder, and it has turned out that the instrument had been passed into a false route. With the ordinary staff one cannot be certain where it has gone to, and, to remedy the defect, a bollow staff has been used. The second objection is not so grave. When the ordinary staff is employed its shoulder marks out where the stricture begins, and accordingly the surgeon possesses the requisite information to enable him to fix, accurately, the spot for piercing the tissues; but, on the other hand, he does not know exactly where the stricture ends, and is obliged to grope about and feel his way bit by bit. Hence it is that when the staff is witbdrawn it is sometimes difficult, and occasionally impossible, to introduce a catheter into the bladder, either because some distal tags of the stricture have not been divided, or that the incision into the urethra forms a kind of bay-window in which the catheter catches. Mr. Marshall has remedied this latter objection by adopting Mr. Thomas Wakley's principle of sliding an elastic catheter over the staff, which thus served as a guide.* Unless, however, the situation of the staff is absolutely assured, this remedy is of but secondary value. Everything hinges upon the position of the instrument.

Some time ago, when searching for a guide for subcutaneous urethrotomy that would be free from the objections alluded to, I perceived that if a longitudinal piece were cut out of the convexity of the metal catheter employed by Mr. Thomas Wakley, a groove would then be formed for the knife to run in; and that if a slit were made in the ferrule of the elastic catheter, there would result, from the alterations effected, a compound instrument possessing advantages not attached to any similar one, so far as $I$ was aware of

Mr. Thomas Wakley's instrument consists, as is well known, of several distiact parts. A metal catheter (Fig. 1); a long rod (Fig. 3), to be screwed into the metal catheter (at D); an elastic tube or catheter open at both ends (Fig 2), to be slipped over the united rod and catheter till it arrives at the stricture; and, lastly, a small movable handle (E), which can be passed over and down the rod till it reaches the upper end of the elastic catheter, against which it is screwed tightly, so as to keep its vesical end well pressed against the obstruction. Now if we cut out a long narrow piece (about two inches in length) from the convexity of the metal catheter, we have at once made a groove (B, Fig. 4) for the knife to run in. This groove ought to terminate an inch and a balt from the eye of the instrument. $f$ The

* Sir W. Fergussan long ago invented, or used, a catheter-staff for external urethrotomy. His instrument was a great improvement on the siaff emploied by the late Professor Syme, but it lacked a sliding catheter. + The portion of the catheter that will correspond with the prostatio urethra ought not to be grooved, in order to prevent the extension of the incision into a region where it can never be required. 